\title{
Neonatal repair of persistent fifth aortic arch and aortic coarctation
}

\author{
Abhay A. Divekar, MBBS, MD, ${ }^{\mathrm{a}, \mathrm{b}}$ and Vinod A. Sebastian, MD, ${ }^{\mathrm{b}}$ Denver, Colo
}

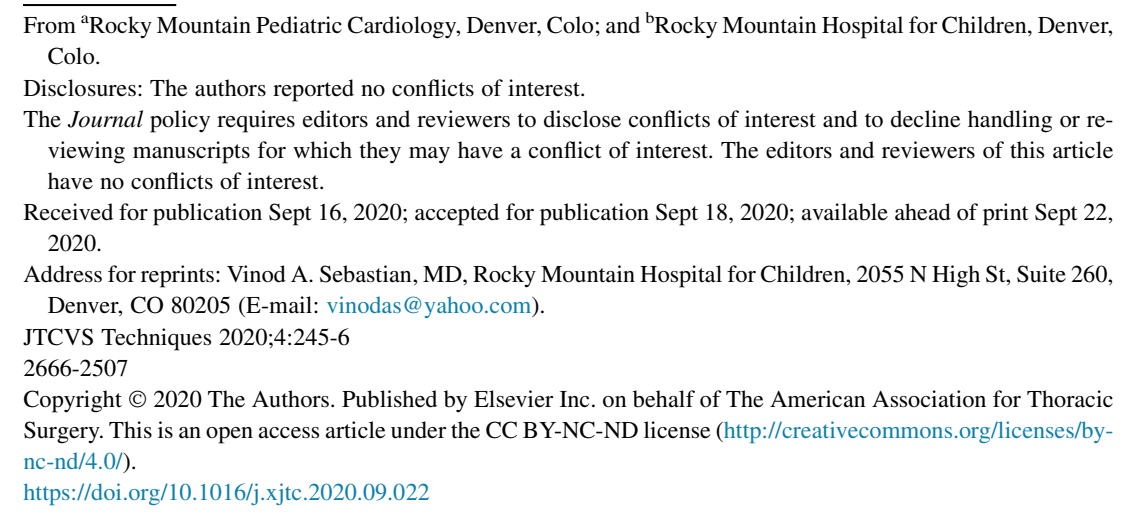

$\checkmark$ Video clip is available online.

There are 2 main clinical forms of persistent fifth aortic arch (PFAA), a systemic to systemic connection; that is, the double lumen aortic arch first described by Van Praagh in $1969,{ }^{1}$ and the systemic to pulmonary connection variety.

We report a neonatal case of PFAA with severe hypoplasia of the fourth arch, and coarctation of both the fourth and fifth arches. The discrete coarctation segment relaxed with prostaglandin E1 (PGE1). We will review this patient and the literature specifically discussing PGE1-sensitive tissue.

\section{PATIENT AND METHODS}

Informed consent was obtained from the patient's parent for this publication. Pediatric cardiology consultation was requested for a $2.9-\mathrm{kg}$ term male neonate who failed a critical congenital heart disease screening test. The patient had weak femoral pulses and echocardiography showed normal intra-cardiac anatomy. Suprasternal imaging showed 2 arches connecting the ascending and descending aorta in superoinferior orientation on the same side of the trachea. The superior arch was severely hypoplastic ( $2 \mathrm{~mm} ; z$ score, -6.3 ), the ductus arteriosus was patent but small, and Doppler interrogation showed typical coarctation flow pattern with mild gradients across both arches. The isthmus of the fourth arch was $2 \mathrm{~mm}(z$ score, -5.77) and of the fifth arch was $1.7 \mathrm{~mm}$. After PGE1 administration, the ductus arteriosus was larger and there was normalization of coarctation flow pattern presumably from relaxation of PGE1-sensitive tissue in the terminal segment of both arches, the isthmus of the fourth and fifth arches now measured 2.5 and $2.7 \mathrm{~mm}$, respectively. Computerized axial tomography scan confirmed the diagnosis (Figure 1). The patient underwent elective surgical repair via a midline sternotomy and selective cerebral perfusion. Intraoperative findings confirmed the diagnosis. All presumed ductal tissue was resected from the fourth and fifth arches, and they were connected in a side-to-side anastomosis forming $50 \%$ to $60 \%$ of the posterior

\section{DISCUSSION}

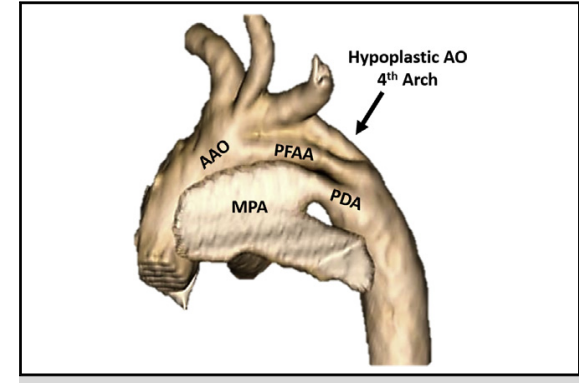

Anatomy of the persistent fifth arch running inferior to the hypoplastic fourth arch.

\section{CENTRAL MESSAGE \\ Except for prostaglandin- sensitive ductal tissue at the aortic or pulmonary end of the persistent fifth aortic arch, the remainder of the arch can be incorporated into the surgical repair.}

See Commentary on page 247.

circumference of the repaired arch. The posterior native tissue was connected to the descending aorta in an interdigitating fashion with anterior augmentation of this repair using a pulmonary homograft patch (Video 1). A small atrial septal defect was also closed. The patient had an uncomplicated postoperative course and the infant was discharged home in 2 weeks. At 1-year follow-up, the patient continues to have an excellent surgical result, normal femoral pulses, and a peak velocity across the arch of $<1.5 \mathrm{~m} / \mathrm{s}$ without diastolic continuation.

Our patient had PFAA with severe hypoplasia of the fourth arch, and juxtaductal coarctation of the fourth and fifth arches. PGE1 administration relaxed tissue in the isthmus of both arches and the Doppler waveform normalized suggesting ductal tissue. Our findings are in keeping with the recognition of PGE1-sensitive tissue in PFAA in the literature. ${ }^{2-5}$ Carroll and colleagues $^{2}$ and Binsalamah and colleagues ${ }^{3}$ have shown histologically that the PFAA contains ductal tissue.

Several different surgical techniques have been successfully utilized to repair arch obstruction/interruption in the setting of PFAA with and without incorporating tissue from the PFAA. ${ }^{2-4}$ Both Lambert and colleagues ${ }^{4}$ and 


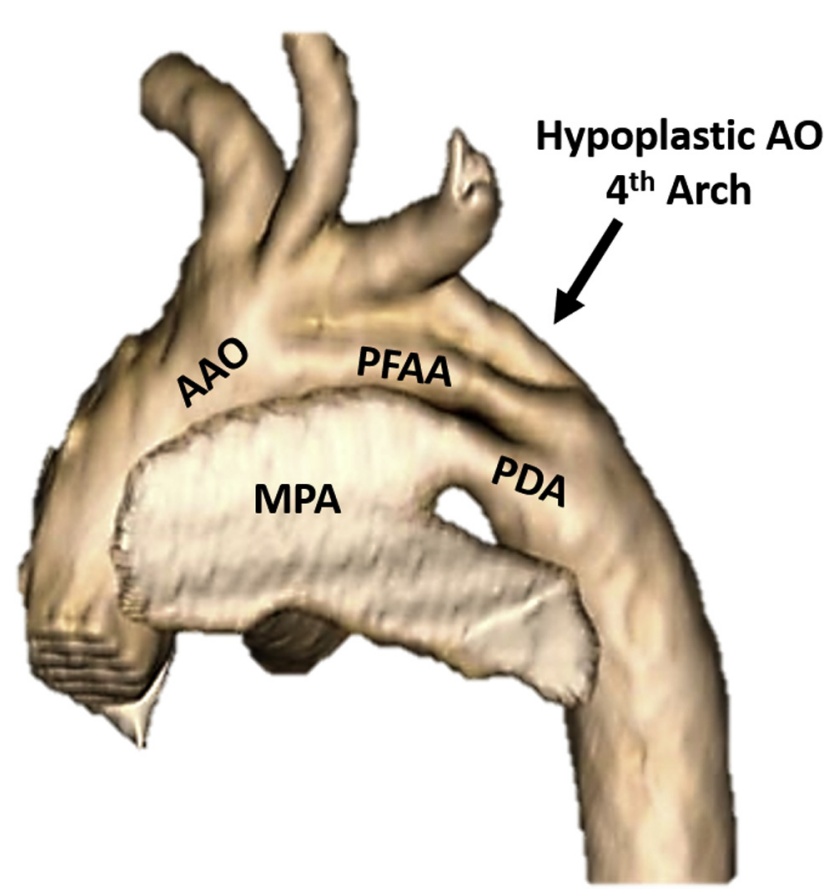

FIGURE 1. Volume-rendered computed tomography angiographic view showing persistent fifth aortic arch (PFAA) connecting ascending aorta $(A A O)$ and descending aorta without any branches. The hypoplastic fourth aortic arch runs superior to the fifth arch. The patent ductus arteriosus $(P D A)$, which is a derivative of the embryonic sixth arch, is inferior to the fifth arch. $A O$, Aorta; $M P A$, main pulmonary artery.

Binsalamah and colleagues ${ }^{3}$ successfully incorporated PFAA tissue into the surgical repair with good immediate and short-term results. Our institutional bias is to repair all patients with hypoplastic arch using patch aortoplasty techniques extrapolated from the Norwood experience. By utilizing the PFAA tissue, we were able to achieve 50\% to $60 \%$ of the circumference composed of native tissue with growth potential compared with $<25 \%$ if the PFAA tissue was not included.

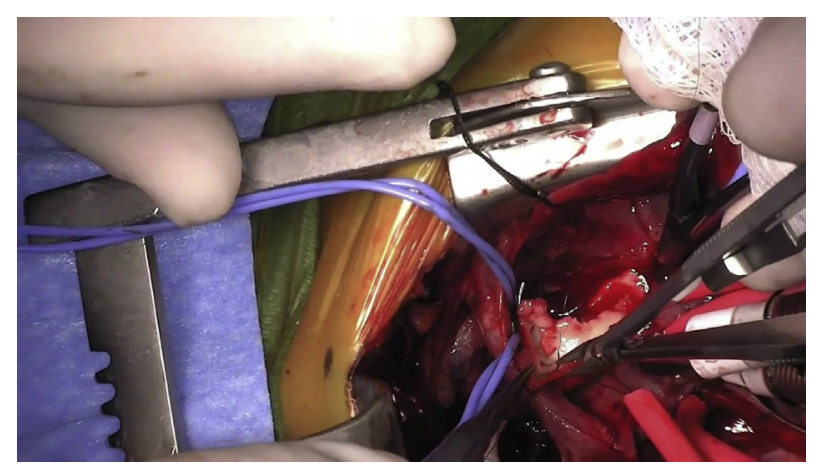

VIDEO 1. Volume-rendered computed tomography scan of the persistent fifth aortic arch (PFAA) followed by surgical repair. Video available at: https://www.jtcvs.org/article/S2666-2507(20)30540-X/fulltext.

\section{CONCLUSIONS}

There is both clinical and histological evidence to show that ductal tissue migrates into the PFAA just like it does in coarctation of the fourth arch. The biggest clinical challenge is complete resection of ductal tissue, and if this can be achieved, it may be reasonable to incorporate PFAA tissue in the repair for its growth potential. Longer-term follow-up and experience from additional case reports will likely provide future guidance given the rarity of this entity.

\section{References}

1. Van Praagh R, Van Praagh S. Persistent fifth arterial arch in man. Congenital double-lumen aortic arch. Am J Cardiol. 1969;24:279-82.

2. Carroll SJ, Ferris A, Chen J, Liberman L. Efficacy of prostaglandin E1 in relieving obstruction in coarctation of a persistent fifth aortic arch without opening the ductus arteriosus. Pediatr Cardiol. 2006;27:766-8.

3. Binsalamah ZM, Chen P, McKenzie ED. Aortic arch advancement for type A interrupted aortic arch with persistent fifth aortic arch type B. Cardiol Young. 2017; 27:1018-21.

4. Lambert V, Blaysat G, Sidi D, Lacour-Gayet F. Double-lumen aortic arch by persistence of fifth aortic arch: a new case associated with coarctation. Pediatr Cardiol. 1999;20:167-9.

5. Zartner P, Schneider MB, Bein G. Prostaglandin E1 sensitive persistent fifth aortic arch type 2. Heart. 2000;84:142. 